Clinical Image

\title{
Atypical cutaneous relapse of multiple myeloma
}

\author{
Jean-Baptiste Rieu ${ }^{1 *}$, Francois Vergez ${ }^{1}$, Jill Corre ${ }^{1}$, Aurore \\ Perrot $^{2}$ and Pierre-Luc Mouchel ${ }^{2}$
}

${ }^{1}$ Haematology Laboratory, University Institute Cancer Toulouse Oncopole, France

${ }^{2}$ Clinical Haematology Department, University Institute Cancer Toulouse Oncopole, France

A 66-year-old patient, diagnosed $\kappa$ light chains MM with $\mathrm{t}(11 ; 14)$, presented before second cycle with bendamustinedexamethasone. A complete remission was initially obtained with bortezomib-cyclophosphamide-dexamethasone and autologous HSCT. After relapse, he was successively treated with bortezomib-dexamethasone, carfilzomibdexamethasone, daratumumab-dexamethasone and bendamustine-dexamethasone. SFLC measurement indicated a partial response but clinical examination revealed a soft pink skin lesion of four centimeters on the left side of the abdomen (A). Puncture of this lesion showed an infiltration of dystrophic plasma cells, with high nucleus-cytoplasm ratio and immature chromatin (B, May-Grünwald-Giemsa, objective $\times 100$ ) (Figure 1). Flow cytometry and genetic analysis con-firmed monotypic $\kappa$ plasma cells with $\mathrm{t}(11 ; 14)$. External beam radiation therapy was a partial failure and bone plasmocytomas appeared two month later.

Cutaneous plasmocytoma in the setting of an established MM is very rare but associated with a poor prognosis. Venetoclax monotherapy was initiated but the general health of the patient declined dramatically before the initiation of the treatment.
More Information

*Address for Correspondence:

Dr. Jean-Baptiste Rieu, Haematology Laboratory, University Institute Cancer Toulouse Oncopole,

France, Email: rieu.jeanbaptiste@iuct-oncopole.fr

Submitted: July 12, 2021

Approved: July 20, 2021

Published: July 21, 2021

How to cite this article: Rieu JP, Vergez F, Corre J, Perrot A, Mouchel PL. Atypical cutaneous relapse of multiple myeloma. J Clin Med Exp Images. 2021; 5: 006-006.

DOI: 10.29328/journal.jcmei.1001022

Copyright: @ 2021 Rieu JP, et al. This is an open access article distributed under the Creative Commons Attribution License, which permits unrestricted use, distribution, and reproduction in any medium, provided the original work is properly cited.

(D) Check for updates

(1) OPEn Access
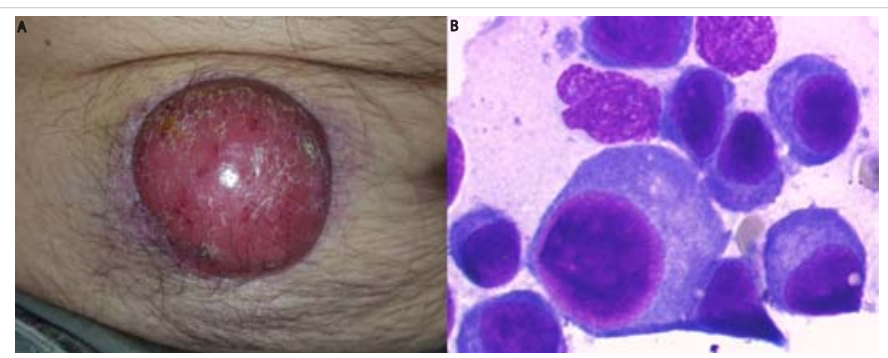